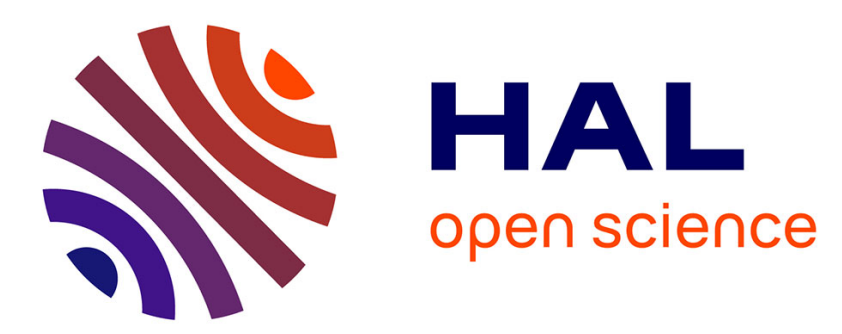

\title{
The Dynamic Characteristics of the Field Emission from the Structures with Quantum Wells
}

\author{
V. Litovchenko, Y. Kryuchenko
}

\section{To cite this version:}

V. Litovchenko, Y. Kryuchenko. The Dynamic Characteristics of the Field Emission from the Structures with Quantum Wells. Journal de Physique IV Proceedings, 1996, 06 (C5), pp.C5-141-C5-146. 10.1051/jp4:1996523 . jpa-00254402

\section{HAL Id: jpa-00254402 https://hal.science/jpa-00254402}

Submitted on 1 Jan 1996

HAL is a multi-disciplinary open access archive for the deposit and dissemination of scientific research documents, whether they are published or not. The documents may come from teaching and research institutions in France or abroad, or from public or private research centers.
L'archive ouverte pluridisciplinaire HAL, est destinée au dépôt et à la diffusion de documents scientifiques de niveau recherche, publiés ou non, émanant des établissements d'enseignement et de recherche français ou étrangers, des laboratoires publics ou privés. 


\title{
The Dynamic Characteristics of the Field Emission from the Structures with Quantum Wells
}

\author{
V.G. Litovchenko and Y.V. Kryuchenko \\ Institute of Semiconductor Physics, National Academy of Sciences of Ukraine, 45 Prospekt Nauki, \\ Kiev-252028, Ukraine
}

\begin{abstract}
The dynamic characteristics of field electron emission from the layered structures with quantum wells have been qualitatively analysed. The main factor leading to appearance of the high frequency current oscillation is the negative differential resistance, observed under rather high electrical field. Layered structures with superthin barriers (like $\left.\mathrm{Si}-\mathrm{SiO}_{2}-\delta(\mathrm{Si})-\mathrm{SiO}_{2}\right)$ seems to be likely to show this effect. The very narrow resonance peak in the FE-current from $\mathrm{QW}$ system at the definite external fields have been demonstrated.
\end{abstract}

\section{INTRODUCTION}

The steady state characteristics of the field electron emission (FE) from structures with quantum wells (QW) have been studied in some previous works [1-4]. The important characteristic of such a system is the occurrence of the nonmonotonous branches on the Fowler-Norgheim curves and, hence, ocurrence of negative differential resistance $\mathrm{R}_{\mathrm{g}}<0$, especially distinguished under resonance tunneling in QW systems. In such case the time oscillation of current, i.e. generation of current-voltage alternating signals with rather high frequency $\omega_{\mathrm{RT}}$ have been predicted.

The estimation of ${ }^{\omega} \mathrm{RT}$ can be obtained, using the relation for electron of the energy level $E_{i}$ oscillation in the quantum well:

$$
\omega_{\mathrm{RT}} \approx \pi \hbar \mathrm{eF} /\left(2 \mathrm{~m}_{\perp}{ }^{*} \mathrm{E}_{\mathrm{i}}\right)^{1 / 2}
$$

That means that for shallow QW and small effective mass of electron, the frequency of oscillations can be rather high. At reasonable electrical fields it may reach values, which is typical for tunneling processes $\left(>10^{10} \mathrm{~Hz}\right)$.

\section{THE MODEL AND CALCULATION OF FN-CURVES IN CASE OF RESONANCE TUNNELING}

We considered the model shown in Fig.1. The variable parameters of the system were the electron density $\mathrm{N}_{\mathrm{b}}$ in the bulk of the Si substrate, the thickness of the Si QW layer $\mathrm{d}_{2}$ and the thicknesses of $\mathrm{SiO}_{2}$ layers $\mathrm{d}_{1}$ and $\mathrm{d}_{3}$. The fixed parameters were the dielectric constants of the semiconductor material $\varepsilon_{\mathrm{S}}=11.7$ and of the insulator layer $\varepsilon_{\mathrm{i}}=3.9$, the semiconductor-insulator band 
discontinuity $\chi_{\mathrm{Si}}=3.2 \mathrm{eV}$, the insulator-vacuum affinity energy $\chi_{\mathrm{iv}}=0.95$, and the temperature $\mathrm{T}=$ $293 \mathrm{~K}$.

The Fermi energy $\mathrm{E}_{\mathrm{Fb}}$ for bulk electrons in the Si substrate, which are distributed over six equivalent ellipsoidal valleys in $\mathrm{k}$-space, was determined using the following well known formula:

$$
\pi^{2} \mathrm{~h}^{3} \mathrm{~N}_{\mathrm{b}} v^{-1}\left(2 \mathrm{~m}^{2} \mathrm{t}_{1}\right)^{-1 / 2}(\mathrm{kT})^{-3 / 2}=\mathrm{F}_{1 / 2}\left(\mathrm{E}_{\mathrm{Fb}} / \mathrm{kT}\right)
$$

where $v=6$ is the degeneracy factor of the valleys in $\mathrm{Si}, \mathrm{m}_{\mathrm{t}}=0.19$ and $\mathrm{m}_{1}=0.92$ are the transverse longitudinal electron masses in these valleys, and $F_{1 / 2}$ is the Fermi integral of order one half . Formula (2) determines the position of Fermi level relatively to the conduction band bottom in the $\mathrm{Si}$ bulk. If the external electric field $\mathrm{F}$ is applied to the system then the band bending may occur at the surface of the Si substrate, depending on the electron density $\mathrm{N}_{\mathrm{b}}$. It leads to the appearance of a Space-Charge-Region (SCR) near the surface. Neglecting the influence of charged surface states (which was proven for conventional microelectronic technology) the total amount of electrons in the SCR per unit surface area is $N_{S}=F \varepsilon_{0} \varepsilon_{2} /(4 \pi)$. If quantization of the electron states in the SCR takes place (this actually occurs at the high fields used in field emission applications) this density is expressed as the sum of the contributions $\mathrm{N}_{i}^{j}$ from all quantum levels $E_{i}^{j}$ of the quantized electron states in the SCR (index $i$ denotes the number of quantum level in the SCR, while $j$ characterizes the type of valley from which the quantum level originates):

$$
\begin{aligned}
& N_{S}=F \varepsilon_{o} \varepsilon_{2} / 4 \pi=\Sigma_{i, j} N_{i j}=\Sigma_{i, j} n_{i}\left(m_{d j} k T / \pi h^{2}\right) \\
& \mathrm{x} \ln \left\{1+\exp \left[-\left(\mathrm{E}_{\mathrm{i}}^{\mathrm{j}}-\mathrm{E}_{\mathrm{FS}}\right) / \mathrm{kT}\right]\right\}
\end{aligned}
$$

where $n_{j}$ is the degeneracy factor of the valleys of $j$ type.

In the approximation of the triangular potential well, which is valid for the lowest quantum states in the SCR, the following analytical expression for discrete electron spectrum was used:

$$
E_{i} j=\left(\hbar^{2} / 2 m_{3 j}\right)^{1 / 3}\left[(3 / 2) \pi e\left(F / \varepsilon_{s}\right)(i-1 / 4)\right]^{2 / 3}, \quad i=1,2,3, \ldots
$$

This formula gives the position of levels $\mathrm{E}_{1}^{\mathrm{j}}$ relative to the conductive band bottom at the surface. Substituton of Eq.(3) into Eq.(2) allows one to determine the position of the Fermi level $\mathrm{E}_{\mathrm{Fs}}$ in the SCR.

The emission current is determined by the sum of two contributions, $\mathrm{J}=\mathrm{J}_{\mathrm{b}}+\mathrm{J}_{\mathrm{S}}$, where the bulk contribution $J_{b}$ is the following :

$$
J_{b}=\Sigma_{j}\left[e_{3 j} k T /\left(2 \pi^{2} \hbar^{3}\right)\right] \int_{0}^{\infty} \ln \left\{1+\exp \left[-\left(W-E_{F}\right) / k T\right]\right\} D_{j}(W) d W
$$


where $D_{j}(W)$ is the transmission coefficient for the electron with the transverse energy $W$, $\mathrm{E}_{\mathrm{F}}=\mathrm{E}_{\mathrm{Fs}}$ is the Fermi energy level which is common for the whole substrate including the SCR, and $\mathrm{W}=0$ corresponds to the position of the conduction band bottom at the Si substrate surface. For the contribution from the quantum levels in the SCR we used the following formula from our previous work [3]:

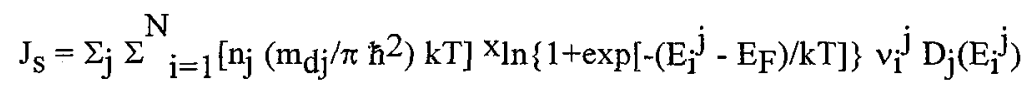

where $v_{i}^{j}$ is the frequency of electron oscillations on the level $E_{i}^{j}$ in the triangular SCR well.

The transmission coefficient $D_{j}$ was calculated on the basis of numerical solution of the Schrödinger equation for the considered system, starting from the vacuum region with the wave function of the quasiclassical type

$$
\psi_{\mathrm{V}}=\mathrm{C}\{2[\mathrm{~W}-\mathrm{eV}(\mathrm{z})]\}^{-1 / 4} \exp \left[\mathrm{i} \int_{\mathrm{zo}}^{\mathrm{z}} \mathrm{dz} \sqrt{2}[\mathrm{~W}-\mathrm{eV}(\mathrm{z})]\right]
$$

and using the boundary conditions $\psi_{+}=\psi_{-}$and $\left(1 / \mathrm{m}_{+}\right) \mathrm{d} \psi_{+} / \mathrm{dz}=\left(1 / \mathrm{m}_{-}\right) \mathrm{d} \psi_{-} / \mathrm{dz}$ at the interfaces to obtain the continuous quantum flux. Here $W$ is the transverse energy ( $W=0$ corresponds to the position of conduction band bottom of the Si substrate surface), and V(z) is the potential barrier.

Fig. 2 demonstrates the current/field characteristics in Fowler - Nordheim coordinates for the system with $\mathrm{N}_{\mathrm{b}}=10^{19} \mathrm{~cm}^{-3}, \mathrm{~d}_{1}=\mathrm{d}_{2}=\mathrm{d}_{3}=10 \AA$, and $(100) \mathrm{Si}$ orientation. In this case the degeneracy factor $n_{j}$ for valleys with heavy $m_{3 j}$ electron mass $(j=1)$ is $n_{1}=2$, while with light $\mathrm{m}_{3 \mathrm{j}}$ mass $(\mathrm{j}=2) \mathrm{n}_{2}=4 ; \mathrm{m}_{3}(\mathrm{j}=1)=0.92, \mathrm{~m}_{3(\mathrm{j}=2)}=0.19$.

In Fig. 3. the emission currents from the system with $\mathrm{QW}$ and without $\mathrm{QW}$ are compared for the case of $\mathrm{N}_{b}=10^{19} \mathrm{~cm}^{-3}$ in both systems. It follows from this figure that the introduction of the additional QW layers leads to a substantial increase in emission current from the system at definite fields (when effective resonant tunneling occures) and makes it possible to achieve emission currents even higher than from the system without such an additional layer. In the insert the relation of the current from the QW system to that from the system without QW is shown. It demonstrates that pronounced resonance peaks exist in the current from the QW system at definite external fields. The detailed calculation of RT -peak, Fig.2b,.show the very narrow, monochromatic character (about $20-30 \mathrm{~V} \mathrm{~cm}^{-1}, \Delta \mathrm{V} \sim 10 \mathrm{mV}$ ). Also the appearing of the negative differential resistance have been demonstrated by Fig. 3 .

\section{SOME DYNAMIC CHARACTERISTICS.}

Resonance tunneling, which can be realised in the double (or many) QW system, gives not only the negative resistance regime of FE-current (as has been demonstrated, in particular, in [4] ), but also leads to specific enhanced kinetic properties as compared with single $Q W$ tunneling. In the case of resonance structures the tunneling time corresponds to the life-time $\tau_{R T}$ of the resonance 
state as defined by Luryi [5]. The calculation of $\omega_{\mathrm{RT}}$ on the base of a collision frequency with the walls of barrier, however, overestimates it's value [6].

In [6] a rather concrete method for ${ }^{\mathrm{R} T}$ estimation has been proposed by Choe et al. This socalled "Complex representation method for energy" took into account the energy levels in both of the QW's and thelifetime for the metastable states of a system. In a double QW system this is defined as

$$
\mathrm{T}=\mathrm{h} / \Delta \mathrm{E}_{\mathrm{ij}}
$$

where $\Delta \mathrm{E}_{\mathrm{ij}}$ is the spacing of the energy doublet in the coupled system.

For the GaAs-AlAs system, with $\varphi_{B}=210 \mathrm{meV}\left(\mathrm{d}_{\mathrm{QW}}=200 \AA, \mathrm{d}_{\mathrm{B}}=100 \AA\right)$, such a method gives the time of resonance tunneling $\tau_{\mathrm{RT}} \approx 10 \mathrm{ps}$ (significantly less than the 5000 ps predicted for nonresonance single QW system).

For the SCR QW case we have relation for $1 / T$, which in fact has a same meanning as proposed by formulae (8), namely is the oscillation frequency in the QW :

$$
v_{\mathrm{SCR}}=\mathrm{eF} / 2\left(2 \mathrm{~m}_{\mathrm{Z}}{ }^{*} \mathrm{E}_{\mathrm{ij}}\right)^{1 / 2} \propto \mathrm{CF}^{2 / 3} / \mathrm{m}_{\mathrm{Z}}{ }^{*} 1 / 3
$$

For film QW structures:

$$
\left.v_{F}=e \varphi_{B} / 2 d_{Q W}\left(m_{z}^{*} E_{i j}\right)^{1 / 2}\right) \propto E_{i j}^{1 / 2} / d_{Q W}
$$

If we adapt the Choe et al model to our case FE structure (taking into account differences in $\mathrm{d}_{\mathrm{QW}}$ $, \mathrm{d}_{\mathrm{B}}, \mathrm{m}_{\mathrm{Z}}{ }^{*}, \varphi_{\mathrm{B}}$, etc.) we obtain a value of the same order as value in [6] (due to narrower barriers for $\mathrm{FE}$ structures) i.e. $v_{\mathrm{F}} \approx 10^{11} \mathrm{~Hz}$.

That means, that these systems have a frequency oscillation at resonance tunneling order $0.1 \mathrm{THz}$, i.e. values are very high.

The curves illustrating the field dependences of the $\omega_{\mathrm{F}}$, are shown on Fig. 4.

To solve the problem of real generation of the alternating FE current such an order of frequency it is important to consider the electrical circuit parameters of resonator, i.e. the capacitance and negative resistance values. So to achieve the indicated above superhigh values of $\omega$, we have to choose materials with rather small $\mathrm{z}$-effective mass $\mathrm{m}_{\mathrm{Z}}{ }^{*},\left(\omega \sim \mathrm{m}_{\mathrm{Z}}{ }^{*}-1 / 3\right)$, as well as to use not very narrow and deep $Q W$ as well as high electric fields $F$.

\section{CONCLUSION}

The analysis for frequency parameters of the field emission structures with quamtum wells hase been performed. Especially high parameters of generation of the field current oscillation take place under resonance tunneling (TeraHerz frequences). Estimation relating to structures of practical interest have been made. 


\section{Acknowledgments}

This work was supported by ISRF-96, CRDF N849

\section{References}

[1] V.G. Litovchenko, Yu.V. Kryuchenko, J. Vac. Sci. Technol., B11(2) (1993) 362.

[2] V.G. Litovchenko, Yu.V. Kryuchenko, L.I. Il'chenko, J. Micromech. \& Microeng., 3 (1993) 74.

[3] L.I. Il'chenko, Yu.V. Kryuchenko, V.G. Litovchenko, Appl. Surf. Sci., 87/88 (1995) 53.

[4] Yu.V. Kryuchenko, V.G. Litovchenko, J. Vac. Sci. Technol., B14(3) (1996) 1.

[5] S. Luri, in: High Speed Semiconductor Devices, ed. by Sze (NY, 1990) p.225.

[6] W. Choe et al., J. Appl Phys. 79(10) (1996) 7510.

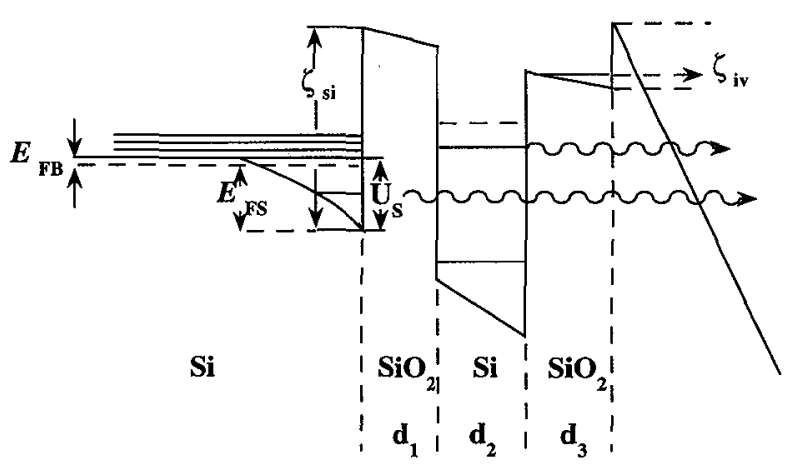

Fig. 1. Band structure of the field emitting layered structure ( $\mathrm{Si}-\mathrm{SiO}_{2}-\mathrm{Si}-\mathrm{SiO}_{2}$-vacuum) 

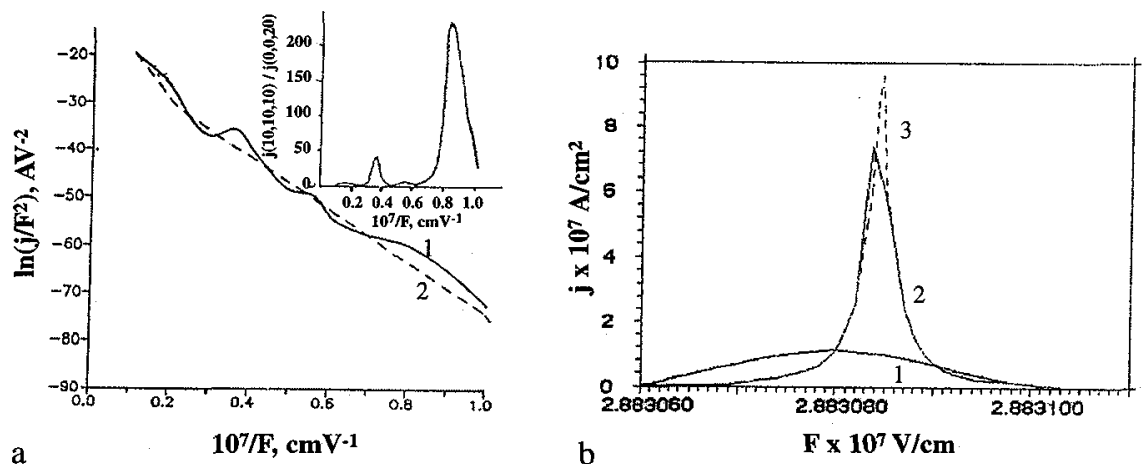

Fig. 2. a) Fowler-Nordheim current for some structures: 1) $d_{1}=d_{2}=d_{3}=10 \AA$; 2) $d_{1}=0, d_{2}=0, d_{3}=20 \AA$. On insert is the normalized two $Q W$ current to current of the single $\mathrm{QW}$ system.

b) Calculation of RT peak at small steps of 1) $\Delta \mathrm{F}=10^{5} \mathrm{Vcm}^{-1}$; 2) $10^{4} \mathrm{Vcm}^{-1}$;

3) $10^{3} \mathrm{Vcm}^{-1}$.

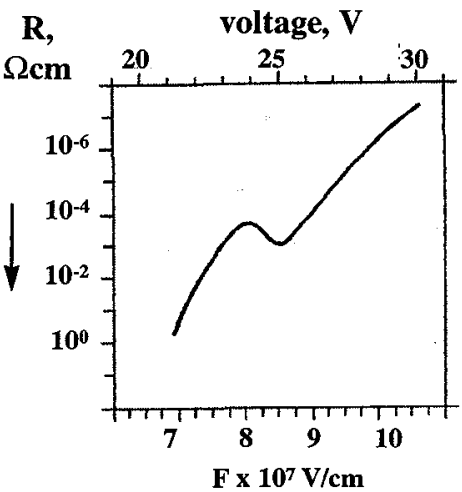

Fig. 3. Resistance dependence of the field emitting layered structure versus applied voltage $V$ (field strength) under resonance tunneling (for parameters Fig. 2a,1).

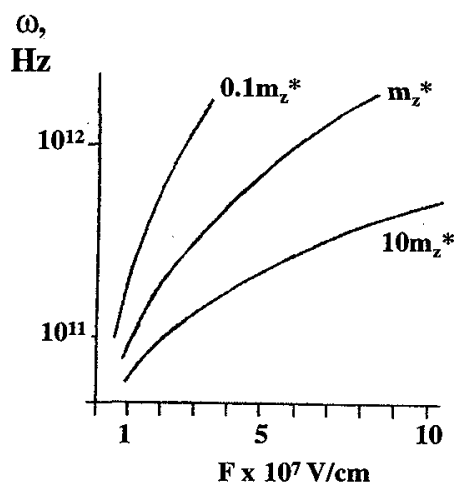

Fig. 4. Frequency of the field emission current oscillations in field emitting structures under different transverse effective masses. 